Artículos/ Articles

\title{
Consumo, crisis y clases medias: cambios y continuidades en los discursos sobre el consumo de la clase media española ante la Gran Recesión de 2008
}

\author{
Consumption, crisis and middle classes: changes and \\ continuities in the discourses of the Spanish middle class on \\ consumption before the Great Recession of 2008
}

\author{
Marc Barbeta-Viñas \\ Universitat Autònoma de Barcelona, España. \\ marc.barbeta@gmail.com
}

Recibido / Received: 03/05/2021 Aceptado / Accepted:22/06/2021

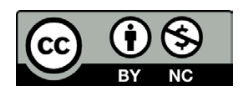

\section{RESUMEN}

El objetivo del trabajo es abordar los discursos que desarrollan las clases medias españolas en torno al consumo antes de la crisis económica de 2008 y su evolución una vez iniciada la crisis. Se propone analizar los sentidos construidos sobre el consumo, así como calibrar en qué medida estos discursos se han ido modificando a través de "cortes discursivos" con el advenimiento de la gran recesión, de acuerdo con la literatura existente. La base metodológica y empírica del trabajo es cualitativa: se analizan cinco grupos de discusión realizados en diversas ciudades españolas en 2004. El método de análisis desarrollado sigue la orientación sociohermenéutica del análisis sociológico del discurso. Los resultados aportan luz sobre el papel cínico y legitimador de parte de las clases medias en relación al consumo pre-crisis, así como evidencian el impacto de los periodos de crisis sobre las imágenes y valoraciones de las relaciones de consumo.

Palabras clave: Consumismo, crisis económica, clases medias, análisis discurso, grupos discusión.

\begin{abstract}
This paper addresses the discourses that develop part of the Spanish middle classes about consumption before the economic crisis of 2008 and its evolution once the crisis has started. It is proposed to analyze the senses built on consumption, as well as to calibrate the extent to which these discourses have been modified through of "discursive cuts" with the advent of the great recession, according to the existing literature. The methodological and empirical basis of the work is qualitative: five discussion groups conducted in various Spanish cities in 2004 are analyzed. The method of analysis
\end{abstract}


Consumo, crisis y clases medias: cambios y continuidades en los discursos sobre el consumo de la clase media española ante la Gran Recesión de 2008

developed follows the socio-hermeneutical orientation of the sociological discourse analysis. The results provide light on the cynical and legitimizing role of the middle classes in relation to consumption in pre-crisis periods, as well as evidence of the impact of periods of crisis on the images and valuations of consumer relations.

Keywords: Consumerism, economic crisis, middle classes, discourse analysis, focus groups.

\section{INTRODUCCIÓN}

Con el fin de conocer la evolución discursiva sobre el consumo desarrollada por las clases medias españolas en el transcurrir de una crisis, en el presente trabajo se analizan los discursos en torno al consumo de estos sectores sociales antes de la crisis económica y financiera de 2008.

La gran recesión supuso un fuerte impacto en las prácticas y representaciones sobre el consumo, especialmente en países como España. Sus efectos se hicieron notar en distintos ámbitos y sobre franjas importantes de la población, si bien con relación al consumo se sintieron de modo específico entre algunas fracciones de las clases medias. Estos sectores habrían visto truncadas sus expectativas y prácticas de consumo, hasta tal punto que la percepción social dominante, influida además por una creciente polarización social, sería la de su desaparición paulatina a partir de la crisis económica (Alonso et al., 2017; López y Rodríguez, 2010). Este panorama desolador tendía a contrastar con la euforia producida por el consumo intensivo de la década anterior. Un consumo que se configuraba como terreno de juego donde se resolvían los principales dilemas sociales: singularidad, éxito social y una profusión de objetos a los que buena parte de la clase media española aspiraba (Alonso, 2016).

Algunos trabajos muestran cómo con las crisis las relaciones de consumo se ven afectadas por una doble vía: una vinculada a los recursos económicos y con impacto directo sobre los gastos; y otra vinculada a las creencias de tipo cognitivo y/o emocional (Koos, 2017). Respecto a la primera, trabajos realizados en distintos países señalan un descenso moderado del consumo (Angelini et al., 2013; Vihalemm et al., 2016; Lopes y Frade, 2012). En el caso de España, durante los primeros años de la crisis no se produjeron cambios destacables en la distribución de las compras respecto a años anteriores; sí una disminución general del gasto por parte de las familias, como se observa en el figura 1, lo que sugería el desarrollo de unos hábitos más restrictivos (Salido, 2012; Brändle, 2010).

La segunda vía señala que los comportamientos de consumo pueden verse influidos por las creencias y representaciones que los consumidores construyen en contextos de crisis. Por ejemplo, sobre situaciones sociales concretas como las que se pueden encontrar en relación con el trabajo, a la mayor o menor confianza a la hora de consumir, en las percepciones colectivas sobre el ahorro, las necesidades, etc. En esta perspectiva, a nivel internacional han ido apareciendo numerosos trabajos en los que se analizan las distintas reacciones de los consumidores en el período de recesión (Boost y Meier, 2017; Lekakis, 2015; Hampson y McGoldrick, 2013; Atkinson, 2013).

En el caso español, cabe destacar los trabajos de tipo cualitativo que han indagado sobre el sentido social de los efectos de la crisis sobre el consumo 
(Alonso et al., 2015; 2016a; 2016b; 2017; Callejo, 2010). Estos análisis ponen de manifiesto el disciplinamiento que impuso la crisis en buena parte de la población. No solamente en los sectores que se vieron forzados a contener los gastos, sino también en grupos sociales más amplios sobre los que había emergido el miedo, la incertidumbre y la inseguridad ante los efectos que podía tener la crisis en ámbitos como el trabajo, la disminución de ingresos y el consumo (véase figura 2).

Figura 1. Evolución del gasto en consumo de los hogares per cápita en España (1970-2018)*

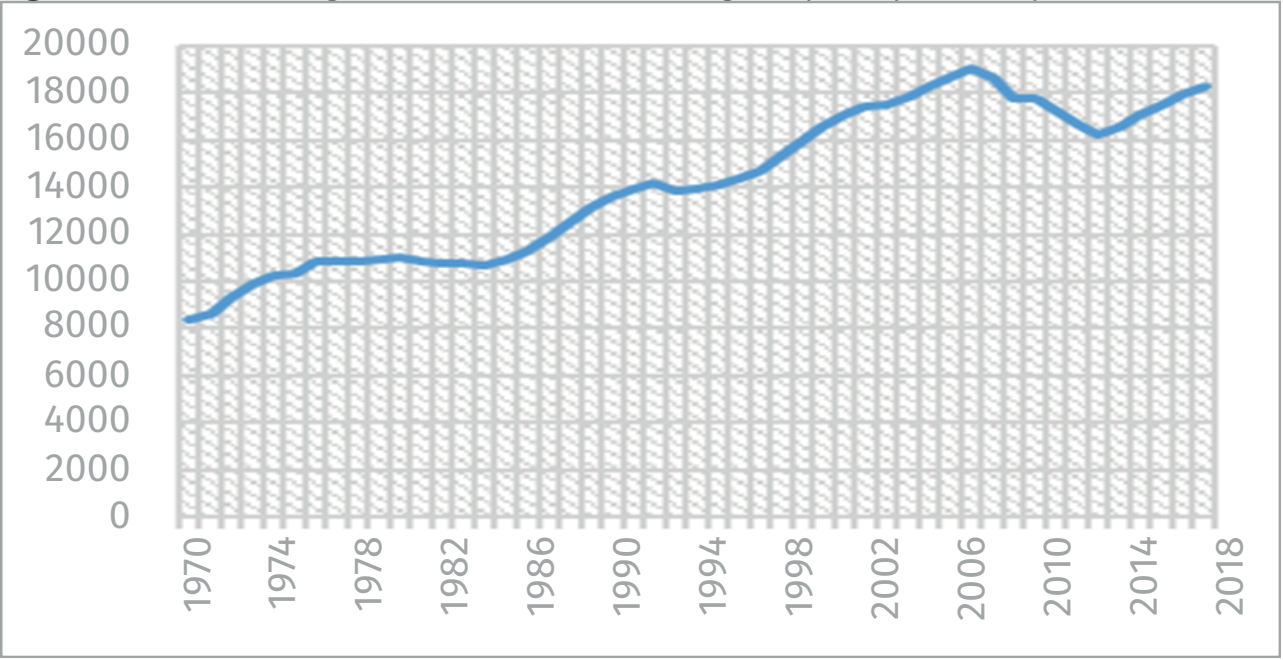

Fuentes: Elaboración propia a partir de datos del Banco Mundial y del INE. * US\$ a precios constantes de 2010.

Figura 2. Evolución tasa de paro en España (1976-2015)

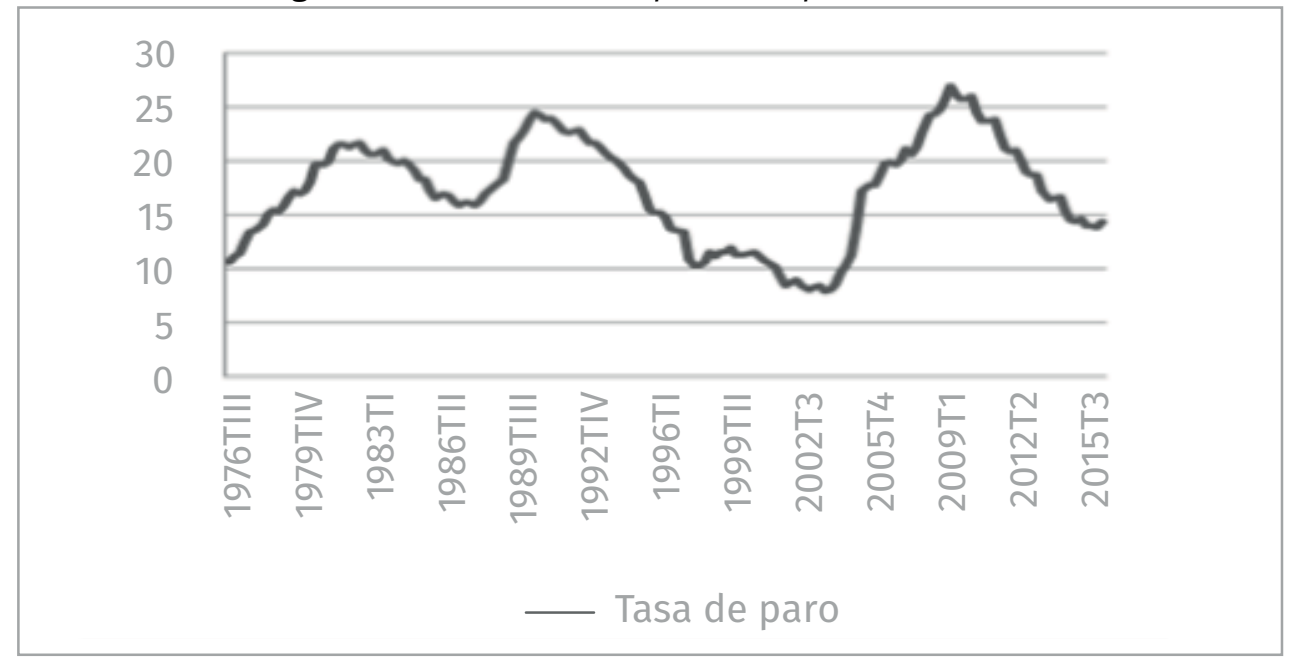

Fuentes: Elaboración propia a partir de datos del Banco Mundial y del INE. 
Estas investigaciones, sin embargo, señalan diferencias entre clases sociales en las representaciones sobre el consumo. Las clases bajas habrian mantenido un discurso en el que se relativizan los efectos de la crisis en sus formas de consumo (Arnal, et al., 2020; Alonso et al, 2016b; Lekakis, 2015). Las clases medias en cambio (en particular autónomos, empleados, pequeños empresarios), son las que se habían visto más amenazadas por la crisis, lo que influyó en la construcción de sus significaciones sobre este ámbito. El inicio de la recesión había hecho aflorar un discurso moral en estos sectores medios según el cual la crisis sería el precio y castigo que la población tendría que pagar por años continuados de "consumo exacerbado'. Ello supondría una culpabilización colectiva de los consumidores por "haber vivido por encima de sus posibilidades" (Alonso et al, 2015 y 2016b; Callejo, 2010). A pesar de encontrar otros discursos en análisis posteriores (Alonso et al, 2016a y b), estos resultados sugieren que las clases medias españolas habrían asumido el haberse movido, en años anteriores, por un fuerte reconocimiento que pasaba por la práctica consumista. Ello se explicaría, en parte, porque la clase media había sido el grupo social más comprometido con el consumo superfluo, las estrategias de diferenciación, y el más sensible a la presión de la cultura de consumo, ya desde los últimos modelos de consumo en España (Alonso y Fernández Rodríguez, 2020; Alonso et al, 2015).

Estos trabajos plantean también que la interpretación moralizante de los hábitos de consumo a partir de la llegada de la crisis habría ido aparejada a una actitud de rechazo a la lógica consumista. Lo que puede haber implicado un viraje en las formas de significar las prácticas de consumo en unas clases medias que, como ya afirmaba Bourdieu (1988, p. 323), su posición estructural las había caracterizado por "vivir más allá de sus posibilidades". Cabe preguntarse entonces ¿Qué sentido tenía el consumo antes de la crisis económica por parte de las clases medias? ¿Se ha producido realmente un cambio y una evolución en las representaciones del consumo? ¿En qué aspectos se ha modificado el discurso en torno al consumo con la llegada de la crisis, teniendo en cuenta que parece haber hegemonizado una valoración crítica (moral) del consumismo?

Si los trabajos dedicados al caso español nos ilustran el relato de los efectos de la crisis sobre el consumo, quedan aún por explorar aquellos discursos en torno al consumo desarrollados unos años antes de la crisis. Este es el objetivo específico del presente trabajo. Concretamente se pretende 1) ahondar en los procesos de racionalización -justificación y legitimación ideológica- de las formas de consumo desarrolladas en esta etapa por las clases medias. Adicionalmente, 2) se propone contribuir a analizar la dimensión diacrónica de los procesos de consumo, poniendo en relación el análisis aquí propuesto con los resultados de las citadas investigaciones cualitativas sobre el impacto de la crisis sobre el consumo en España. Este planteamiento longitudinal, por cuanto se introduce el factor temporal y las reacciones de las clases medias al cambio asociado a una crisis, ha sido habitual en análisis cuantitativos sobre el consumo y el advenimiento de la crisis. No obstante, no ocurre lo mismo con los estudios cualitativos con datos secundarios (Hughes y Tarrant, 2019). Contribuyendo a cubrir este vacío, se introduce una comparación entre los discursos desarrollados en puntos temporales distintos -antes y después de la crisis-, con el fin de investigar los principales cambios discursivos con relación al consumo. Con ello nos proponemos avanzar en el conocimiento existente sobre la evolución del papel de las clases medias, centro social e ideológico de la sociedad de consumo, ante acontecimientos como una crisis económica. 


\section{ENFOQUE TEÓRICO-METODOLÓGICO: CORTES DISCURSIVOS, CLASES MEDIAS Y CONSUMO}

El desarrollo del trabajo va a sustentarse en dos referencias teóricas y metodológicas. La primera parte de la propuesta de Marc Angenot (2010) sobre los cortes argumentativos y las rupturas cognitivas. Estas nociones hacen referencia a los conflictos argumentativos sobre las formas de lo decible, los códigos y los repertorios discursivos de legitimación ideológica que se producen en sociedad en momentos temporales distintos. Inscribiendo el análisis de la significación de las relaciones de consumo en la problemática de los conflictos argumentativos e ideológicos, formulamos la hipótesis -que vamos a fundamentar con el análisissegún la cual la crisis habría supuesto el desarrollo de ciertos cortes discursivos en relación con el consumo en las clases medias. Estos cortes establecerían marcos de sentido divergentes, antes y después de la crisis, en las valoraciones y legitimaciones de los procesos de consumo.

La segunda referencia es relativa a la comprensión y uso del concepto de clases medias y sus relaciones con el consumo. Seguimos, por una parte, la concepción de inspiración marxista de las clases medias de Ortí (1992) -basada en los trabajos de Martin Nicolaus y Erik 0 . Wright- y su propuesta de articulación entre los modelos estructural, jerárquico y analítico. Esta articulación admite la posibilidad de operativizar en términos analíticos categorías propias de modelos históricoestructurales y jerárquicos. Lo que resulta útil, en nuestro caso, para el diseño del trabajo de campo con grupos de discusión.

Tabla 1. Articulación de modelos clasistas de estratificación social referidos solamente a las clases medias y sus estratos.

\begin{tabular}{|c|c|c|}
\hline $\begin{array}{l}\text { MODELO } \\
\text { JERÁRQUICO }\end{array}$ & MODELO ESTRUCTURAL & MODELO ANALIITICO \\
\hline $\begin{array}{l}\text { Clase media- } \\
\text { alta }\end{array}$ & $\begin{array}{l}\text { Nueva pequeña burguesía: } \\
\text { profesionales y estratos } \\
\text { superiores clases medias } \\
\text { funcionales. }\end{array}$ & $\begin{array}{l}\text { Profesionales liberales. } \\
\text { Altos funcionarios superiores. } \\
\text { Gerentes, técnicos, cuadros superiores, empresa } \\
\text { privada. }\end{array}$ \\
\hline $\begin{array}{l}\text { Clase media- } \\
\text { media }\end{array}$ & $\begin{array}{l}\text { Nueva pequeña burguesía: } \\
\text { estratos medios clases } \\
\text { medias funcionales. }\end{array}$ & $\begin{array}{l}\text { Funcionarios públicos civiles (servicios públicos). } \\
\text { Técnicos y cuadros medios empresa privada. } \\
\text { Pequeños empresarios con número reducido de } \\
\text { trabajadores asalariados. }\end{array}$ \\
\hline $\begin{array}{l}\text { Clase media- } \\
\text { baja }\end{array}$ & $\begin{array}{l}\text { Vieja pequeña burguesía: } \\
\text { estratos inferiores clases } \\
\text { medias funcionales } \\
\text { y estratos obreros } \\
\text { superiores. }\end{array}$ & $\begin{array}{l}\text { Pequeños empresarios sin asalariados: } \\
\text { trabajadores autónomos. } \\
\text { Encargados comercio. } \\
\text { Empleados servicios empresa privada. } \\
\text { Funcionarios escala auxiliar. } \\
\text { Dependientes de comercio. } \\
\text { Subalternos servicios públicos. } \\
\text { Capataces y obreros industriales cualificados }\end{array}$ \\
\hline
\end{tabular}

Fuente: elaboración propia a partir de Ortí (1992).

Por otra parte, este enfoque es coherente con los trabajos derivados de Bourdieu (1988) dedicados a las clases medias y al consumo (Lawler, 2005; Skeggs, 2004). De modo que entenderemos las clases no solamente desde su posición social objetiva, sino también en su dimensión cultural y subjetiva. Eso es, unas clases medias que producen simbólicamente el consumo, cuyo sentido depende de cómo valoran, significan y legitiman sus prácticas y objetos de consumo. Así, el 
campo del consumo deviene, fundamentalmente, un campo de luchas simbólicas por la significación y la diferenciación social.

\section{METODOLOGÍA Y DISEÑO}

La base empírica del trabajo es de carácter cualitativo; se han analizado 5 grupos de discusión (GD) realizados a finales de 2004 en importantes ciudades españolas. El diseño de la muestra pretende producir información acerca de los discursos que desarrollaban antes de la crisis respecto el consumo distintos sectores sociales que podemos ubicar en las clases medias (véase tabla 1). La finalidad de este tipo de muestreo de carácter estructural (Ibáñez, 1979) es el de analizar el universo discursivo vinculado a ciertos sectores sociales, por lo que los criterios usados en el diseño presuponen la obtención de cierta variabilidad discursiva, en línea con lo realizado en la literatura citada. Las variables para la composición de los grupos y diferenciación de los estratos dentro de la clase media han sido la posición en los procesos productivos y el nivel formativo. Se ha buscado también un equilibrio en términos de sexo/género, así como cierta homogeneidad en cuanto a la edad/ciclo vital (véase figura 3). Las dimensiones de la muestra pueden tomarse como uno de los límites del trabajo. Sin embargo, cabe señalar que la población objeto son las clases medias de la sociedad, no el conjunto de sectores de la estructura social. Lo que hace que cinco grupos de discusión hayan sido suficientes para analizar los campos semánticos principales sobre el consumo y las posiciones ideológicas que los fundamentan. No podemos descartar, eso sí, que nuevos grupos añadiesen algunas variaciones y particularidades discursivas.

Figura 3. Diseño de los grupos de discusión

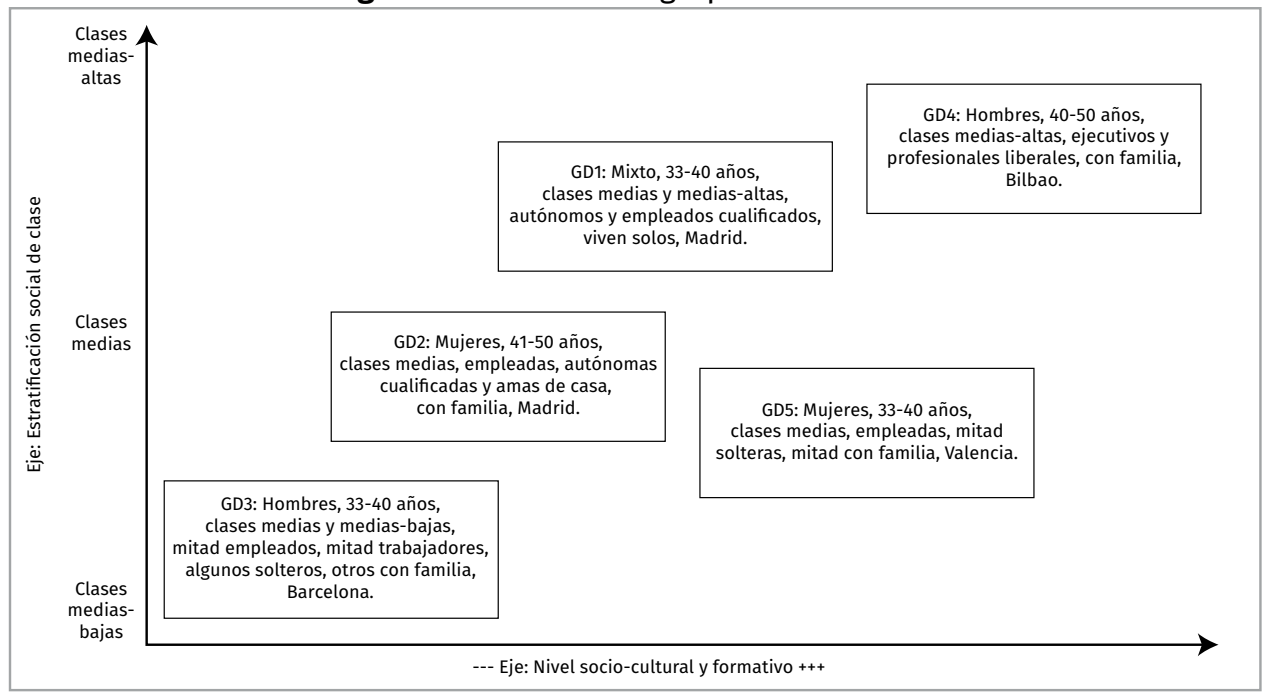

Fuentes: Elaboración propia.

El uso de los grupos y el método de análisis siguen los postulados del análisis sociológico del discurso en su versión sociohermenéutica elaborada por Conde (2009), Ortí (2014) y Alonso (2013), entre otros. Este enfoque plantea un análisis 
semántico articulado con un análisis pragmático de los enunciados discursivos (textos) que los consumidores desarrollan desde sus posiciones sociales. El análisis del discurso nos sirve aquí como una herramienta para conocer y explicar los universos ideológicos con los que los actores sociales interpretan los procesos de consumo. Los discursos ideológicos que pretendemos analizar devienen elementos constitutivos de la vida social, siendo expresión concreta de las ideologías en tanto que codificadoras y reguladoras de las experiencias sociales, así como elementos que impulsan y justifican la acción (Ricoeur, 2001).

La estrategia analítica ha consistido en analizar las dimensiones principales del campo semántico del consumo definido por los grupos. Se han reconstruido, primero, algunos de los espacios semánticos y tópicos sociales sobre la cuestión. Esta reconstrucción nos ha permitido, posteriormente, hallar algunas posiciones discursivas básicas, así como los hilos argumentales que desarrollan los distintos espacios (Conde, 2009). Dados nuestros objetivos, hemos privilegiado aquellos elementos del discurso orientados a la construcción de legitimidades de las prácticas de consumo.

Los grupos fueron realizados por la empresa CIMOP de estudios de mercado en el marco de una investigación sobre la evolución del consumo, los estilos de vida y la valoración publicitaria. Para el presente trabajo nos centraremos en los ejes en que las dinámicas de los grupos abordaban los cambios y experiencias en el consumo, los valores y prácticas predominantes en este ámbito, así como las perspectivas de futuro. El impulso inicial en todos los grupos versó sobre la organización de la vida dentro y fuera del hogar, así como el papel de la tecnología, el confort y el diseño. En estos años de crecimiento económico (véase figura 4) se preveía encontrar en todos estos temas el consumo como elemento rector, así como distintas posiciones ante el modelo de consumo vigente.

Figura 4. Tasa anual de crecimiento del PIB (en \%) 1996-2020

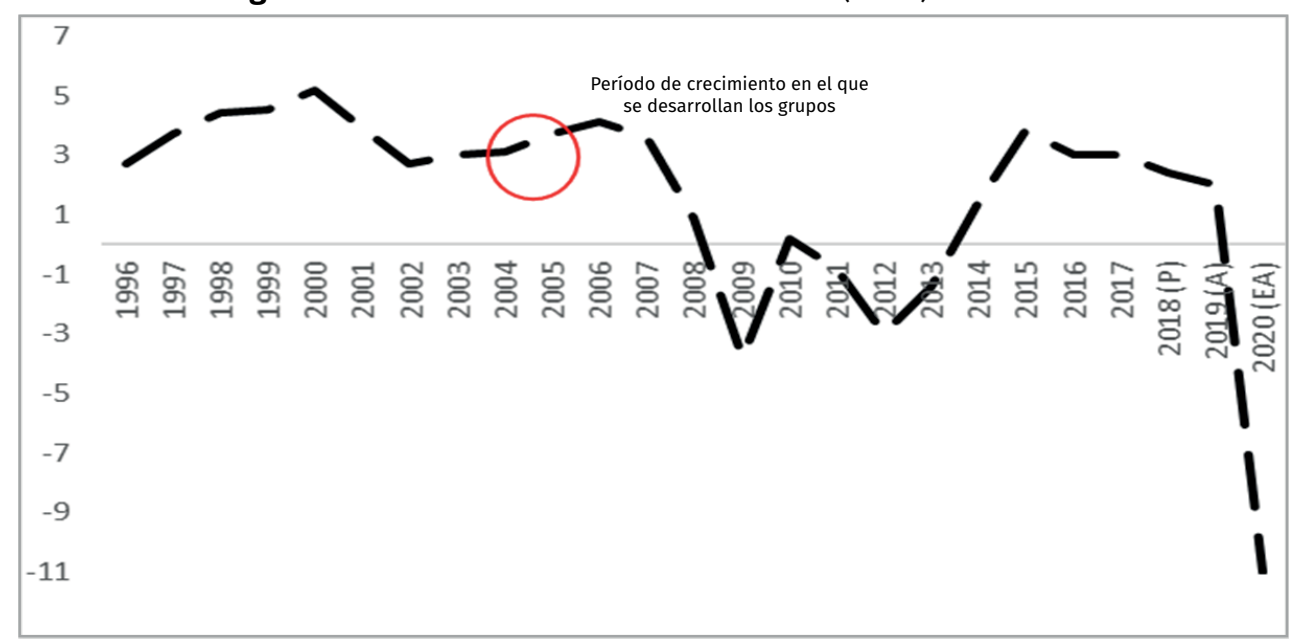

Fuentes: Elaboración propia a partir de datos del INE.

La singularidad de los datos utilizados en la presente investigación viene dada por ser de tipo secundario - no muy habitual en investigaciones cualitativas- y alejados en el tiempo, en un marco de investigación original distinto al que aquí presentamos. Esta estrategia de reutilización y uso de datos secundarios cualitativos ha proliferado en 
los últimos años, entre otras razones, por las posibilidades brindadas por la tecnología digital, que permite almacenar y facilitar el acceso de importantes cantidades de datos, así como -todo hay que decirlo- por la falta de recursos para la investigación. Más allá de las reflexiones metodológicas y epistemológicas que pueda suscitar este tipo de estrategias, las cuales empiezan a abundar (Hughes y Tarrant, 2019; Davidson et al., 2020), lo relevante es destacar las posibilidades brindadas en el presente trabajo, así como sus limitaciones.

Primero, el acceso a los datos ha permitido el surgimiento de preguntas de investigación sin el cual no habrían podido abordarse, permitiendo asimismo un enfoque longitudinal en el análisis. El hecho de tener un objeto de estudio de considerable amplitud como son los procesos de racionalización de las prácticas de consumo en general, ha facilitado abordar el corpus discursivo desde unos objetivos distintos a los de la investigación original. En cierta forma, ello ha supuesto un valor añadido porqué los elementos, temas u orientaciones que prefijaban el discurrir de las dinámicas y los discursos no han sido los relevantes para el análisis aquí propuesto. De manera que se puede suponer un desarrollo menos encorsetado de los discursos en relación al guión y a la lectura realizada. Sin embargo, no puede desconsiderarse una cierta influencia de los temas de interés del estudio original y el desarrollo de los grupos. Además, existe la limitación evidente, dada lo no presencia del autor de este artículo en la moderación de los grupos, de la imposibilidad de introducir matices en las dinámicas de grupo, con el fin de indagar nuevas aportaciones, consensos o evaluaciones sobre lo dicho en los grupos, así como tener menos familiarización con las mismas dinámicas. Una buena transcripción literal ha compensado esta última y particular situación.

Segundo, dado que la contextualización es relevante para la interpretación de los discursos, tanto en la parte introductoria de este trabajo como en el análisis ha sido un aspecto que se ha tenido en consideración. Pero, lo más relevante, es que la recontextualización de los discursos que conlleva el paso del tiempo ha proporcionado unas claves interpretativas que, como se mostrará, difícilmente hubieran surgido en la investigación original, dado que no se contaba con el marco de conocimiento y valoraciones presentes. Se ha hecho evidente así que de la posibilidad de interrogar el corpus desde nuevos objetivos y contextos, puede resultar la emergencia de nuevos sentidos. La orientación sociohermenéutica que seguimos plantea una interpretación contextual de los discursos que abre dicha interpretación a nuevas posibilidades de sentido, vinculadas en este caso, también, a espacios sociales e históricos actuales. Seguimos aquí las reflexiones de Ricoeur (2004) acerca de los textos narrativos según las cuales el discurso escrito no solo se refiere a lo que es, sino que el lector puede llevarlo hacia su exterioridad; es decir, a lo que puede ser en la resignificación del mundo.

\section{RESULTADOS: ANÁLISIS E INTERPRETACIÓN}

\section{La oportunidad consumista: sentidos y legitimación del consumo antes de la crisis de 2008}

En 2004, año en el que se realizaron los grupos sometidos a análisis, España constituía un país con un modelo de consumo maduro homologable a los países de la UE, si seguimos los datos de la Encuesta de Presupuestos Familiares (INE 2005). Desde mediados de los 90, un contexto de bonanza económica, junto con el desarrollo del sistema crediticio y la proliferación del consumo low cost (Gaggi y Narduzzi, 2006) contribuyeron a propiciar una situación en la que las posibilidades de consumo se ampliaban para casi todas las capas de la población. A pesar de la fragmentación social dominante, o más bien, pivotando sobre la misma, el consumo en su dimensión 
privada y mercantil devenía elemento clave en el desarrollo social y en los distintos estilos de vida. Más allá de la satisfacción de necesidades, sobre el consumo se articulaba la integración, el éxito social, así como la expresión de la propia identidad (Bauman, 2007; Alonso, 2016).

Esta centralidad social adquirida por el consumo fue una constante en las dinámicas del conjunto de los grupos, que en este aspecto se mostraban bastante homogéneas a pesar de representar fracciones de clase algo distintas. El análisis empírico sugiere que en los sectores sociales medios ni se quería ni se podía estar fuera del consumo. El consumo, y en particular su dimensión simbólica, envolvía todos los ámbitos de la vida cotidiana, no solamente los estrictamente ociosos, donde suele desarrollarse con más fuerza, sino también aquellos vinculados con el lugar de residencia, el trabajo, hasta el propio cuerpo (dietas, cirugía estética). Esta lógica simbólica del consumo -el valor signo en términos de la semiología-, según expresaban los consumidores, por vía de los dictados de la moda, de la imagen, se erigía como regulador principal de todo intercambio y objeto de consumo. Los discursos no realizaron prácticamente ninguna referencia a ámbitos sociales donde el consumo no jugase un papel primordial. Quedarse fuera del consumo para estas clases medias podía generar, como lo confirman los trabajos realizados después de la crisis, un fracaso social vivido dramática y culpabilizadoramente (Alonso et al., 2015).

$\mathrm{H}$ : Vivimos en el mundo de la imagen exterior, de signos externos: qué marca es el reloj, la camisa, qué coche usas, dónde vives... Entonces para mí tal vez identificamos el diseño con la imagen, ¿no? Porque yo por ejemplo me encanta el diseño, pero reconozco que soy muy clásico, ¿no?, en todo: a la hora de vestir, a la hora de comprarme una casa, de decorar una casa, ¿no? (...)

H- El automóvil es imagen... Es un utilitario, pero también estás transmitiendo una imagen. En función del coche que tengas, estás transmitiendo un mensaje a la gente que te ve. No es lo mismo tener un coche (...). Transmites un mensaje (GD1)

A diferencia de lo que ocurre con los discursos después de la crisis, uno de los tópicos en los años anteriores a la misma era la posibilidad, la oportunidad, de poder acceder de forma intensiva a múltiples objetos y diversas prácticas de consumo. Las clases medias-medias especialmente, percibían un clima muy proclive para el desarrollo de formas adquisitivas que podríamos llamar de sobreconsumo (Häkanson, 2014). Se concebía que les había llegado "su turno" en términos de acceso al consumo opulento; afirmaban que "ahora puedes permitirte el lujo" (GD2), algo que era "inconcebible hace 15 años" (GD5). Así justificaban las relaciones de consumo entonces vigentes a través de la pregunta formulada retóricamente ¿y por qué no dejarse llevar por el deseo consumista?

M: ...porque claro, lo tienes todo al lado, las tiendas más maravillosas, las cremas más maravillosas para estar siempre guapa..., en fin, los mejores asesores, lo tienes todo cerca; y claro, ¿qué haces, pasas de todo esto? Bueno, ¿por qué? No... (GD2).

El contexto económico de bonanza se usaba en los discursos para legitimar las prácticas de sobreconsumo, de acuerdo con la creencia de la normalización: se presuponía, como lo corroboran los datos del figura 1, la existencia de importantes volúmenes de consumo entre la población general. El desarrollo de procesos miméticos en el campo del consumo -siguiendo la aplicación de René Girard para el caso español realizada por Alonso y Fernández Rodríguez (2018: 124)-, contribuía a justificar la fantasía del momento (adecuado) para consumir. El acceso generalizado servía, así, como coartada ideológica para seguir consumiendo. Ejemplo de ello es el acceso efectivo a la propiedad de la vivienda en España (López y Rodríguez, 2010). A este contexto se añadían dos cuestiones que favorecían el consumo. Por un lado, la referencia e identificación en varios grupos con la idiosincrasia del modelo de 
consumo español; modelo que, a diferencia del europeo -dicen los consumidores en continuidad con los discursos poscrisis- responde a 'buenos precios' y a una 'mentalidad' que favorece el sobreconsumo. Por otro, la inexistencia (denegadora) de cualquier relato en torno a situaciones productivas y laborales de precariedad que pudiesen desembocar en dinámicas de austeridad y resignación ante el consumo; algo que ocurrirá, en efecto, a partir de la crisis (Alonso et al, 2016a y b). Este discurso sugiere que no se percibían grandes riesgos entre los miembros de los grupos en relación con sus capacidades salariales y adquisitivas. O en todo caso, no eran obstáculo para proferir un discurso que, si bien señalaba los límites que el salario podía ejercer sobre el consumo efectivo, no era suficiente para ejercer de freno o de contradiscurso.

$\mathrm{H}$ : Estos cuatro días que han pasado vete a pedir hotel en cualquier ciudad de España... no hay, están a tope todo. O sea, que si eso no es consumismo ya... la gente habla de que está fatal... pero preguntas ¿Qué has hecho este puente? Pues me he ido a Galicia a comprar marisco... (GD3).

D: Porque si me hace ilusión algo, voy me lo compro y punto.

D: Efectivamente.

D: Hombre...

D: Dentro de nuestros niveles.

D: Yo tengo muchas cosas que me hacen ilusión.

D: Yo le compro las cosas con mucha ilusión, lo que pasa que me gusta que ella también las trate, y las guarde, y las cuide.

D: Yo es que voy y me lo compro.

D: Yo... Ya me gustaría. Pero como no eso...

D: Le doy muchas vueltas, y mi marido: "cómpratelo ya que te quedas sin ello"(...).

D: Yo pienso que la mayoría nos damos los caprichos que queremos, en ge..., dentro de una línea, claro (GD5).

La eficacia ideológica de este discurso proclive al consumismo se plasmaba en la significación de las prácticas de gasto. Este aspecto supone un corte argumental respecto a las concepciones sobre el ahorro y la austeridad posteriores a la crisis. En nuestros grupos no se encuentran referencias claras a comportamientos económicos basados en una contención necesaria de los gastos o en actitudes de resignación ante la imposibilidad de consumir. De ello no se deriva que las dinámicas analizadas se hayan convertido en odas al despilfarro. No obstante, sí se observa una concepción social distinta de la práctica del ahorro, favoreciendo la creciente valoración del gasto, situándolo incluso por encima de los ingresos de las familias.

Por una parte, los discursos de los grupos tenían en común el hecho de señalar el dinero disponible derivado del trabajo como un elemento que en efecto limitaba el consumo. Pero a pesar de ello, las posibilidades de acceso al consumo tendían a ensancharse, a no hacerse dependientes de una norma social moralizante como parece ocurrir con la llegada de la crisis (Callejo, 2010). Esta dimensión normativa del consumo se construía en base a la representación más o menos latente del oportunismo y el posibilismo, como elementos ideológicos rectores de las conductas de consumo. Ello supondrá un corte argumentativo con respecto al desarrollo discursivo que estos sectores sociales medios realizarán en los primeros años de recesión (Alonso et al., 2015). Se observa, por ejemplo, cómo el uso del ideologema afirmativo "que te lo puedes permitir..." (GD3), marcaba uno de los criterios fundamentales que legitimaba las compras. Una formula discursiva 
donde cabían los distintos modos de financiación y pago requeridos por el modelo consumista. La cuestión era cómo se lo manejaba uno en sus amplios márgenes de acción; márgenes que se construían en función de las oportunidades sociales, económicas, financieras, que se vivían como modificables y favorables. Resonaba latentemente la idea del 'todo es posible', abonada por el deseo de los objetos de consumo: "ahora a lo mejor te ajustas un poco y el que se encapricha de algo lo consigue (...) ahora por ti mismo lo consigues" (GD3).

$\mathrm{H}$ : “...nadie se lo podía pagar, cuatro privilegiados; ahora es llevadero, porque

la situación económica permite ir a cazar o ir a esquiar...

$\mathrm{H}$ : Pero porque ha ayudado el tema económico" (GD4).

Se reconocía, en este sentido, el uso generalizado del crédito y la legítima dependencia del consumo respecto a la capacidad de endeudamiento por buena parte de los grupos. Algo que, como observan Alonso et al. (2016b), contrasta con los discursos en plena crisis. Este uso de la deuda, no obstante, ya entonces era irónicamente puesta en cuestión por parte de las clases medias-altas. Su discurso parecía indicar, a través de sintagmas como "el amo de la barraca" (GD4), que el crédito posibilitaba la reducción -más bien imaginaria- de las barreas socio-simbólicas a través del consumo con otros sectores sociales de estatus inferiores.

El sentido de las prácticas de ahorro no era el de responder a una finalidad en sí misma, ni a reservar, mediante estrategias distintas, parte del salario como ocurría en modelos anteriores de ahorro que han vuelto con la crisis (Broost y Meier, 2016; Alonso et al., 2016b). Más bien, el ahorro se concebía y usaba estratégicamente como instrumento al servicio de un aumento diferido de los gastos. Por tanto, de existir, lo ahorrado tendía a emplearse a corto plazo y con finalidades de consumo ocioso.

M: yo veo muchísima gente, parejas de amigos, que están trabajando todo el año y están ahorrando y tal, porque claro, te quieres comprar el coche, y estás pagando la hipoteca del piso, y te has comprado un mueble monísimo, y el cuadro de aquí, y los gastos de diario porque quieres salir, ver esto, ver lo otro... Y luego estás ahorrando todo el año, realmente te permites unas vacaciones de una semana o quince días, de las que vuelves que te pueden cortar a cachitos porque ni te enteras (GD2).

Otra cuestión relevante es la forma como estos consumidores se representan el mercado de consumo y las relaciones que mantienen con él. Enmarcados en una influyente y potentísima cultura de consumo, que avanza y se desarrolla por los medios de comunicación, las nuevas tecnologías y multitud de soportes publicitarios, los consumidores mostraban un conocimiento e interés notables sobre las marcas y productos existentes en el mercado. En un contexto como este de sobreabundancia en la oferta, así como de diversificación de bienes y marcas, los discursos tendían a dibujar y justificar esta diversidad como una suerte de pluriverso simbólico que se materializaba y expresaba en los diferentes gustos, estilos, tendencias y posibilidades de compra. Desde nuevas tecnologías, donde los discursos ubican los mayores cambios, complejidades y evolución, hasta ropa, alimentación, automóviles, productos de aseo y cuidado, viajes, ocio y cultura, etc.

¿Cómo se codifica significativa e ideológicamente esta amplísima oferta que se tenía a disposición? El análisis del discurso sugiere que, aunque con importantes ambivalencias, como veremos, la práctica del consumo se identificaba con la libertad de elección y una vía fundamental para la configuración identitaria de los consumidores. Dos elementos sobre los que, de modo consistente con estos hallazgos, algunos autores sitúan la construcción de las nuevas clases medias (Skeggs, 2004). Esta representación tendía a legitimar la pauta consumista en la medida en que el mercado se interpretaba como institución capaz de proporcionar posibilidades de consumo. De manera que se terminaba identificando la libertad con 
una más bien ilusoria libertad de elección en el mercado de consumo. El consumo se constituía así, ideológicamente, como un espacio democrático (por el acceso) y democratizador (por sus efectos), donde además se daba respuesta a los deseos de satisfacción, valoración social y diferenciación más o menos particularista. Las prácticas de consumo se asociaban a una versión lúdica y ociosa de la fragmentación social y la construcción identitaria, e incluso entre las clases medias y medias-bajas con la idea de que aquello era "calidad de vida" (GD3).

$\mathrm{H}$ : Depende de lo que quieras transmitir. Tal vez quieres transmitir estar en línea con la mayoría de la gente, o con un grupo determinado de gente, o tal vez quieres transmitir: "oye, mira, yo soy diferente al resto" (...). Depende también el mensaje que quieres transmitir a los demás, de: "yo soy como el resto; yo soy diferente al resto; yo soy rebelde; yo soy....

M: Es fantástico la posibilidad de crearte tú a ti mismo (GD1).

$\mathrm{H}$ : Yo a eso le llamo un poco calidad de vida, al consumismo este, creo que las cosas se hacen para un bien, y si trabajas y te lo puedes permitir pues está bien.

H: La cuestión es esa, que sí te lo puedes permitir, eso es lo primordial (GD3).

M: Hay una oferta ahora en cualquier supermercado que te llevarías..., que hay cosas..., te llevas cosas que en realidad no necesitas, sino por probarlas, porque te atraen o lo que sea... (GD5).

\section{El reverso de la oportunidad: rechazo del consumismo excesivo}

A pesar de lo dicho hasta aquí, un discurso crítico con el consumismo aparecía en los grupos, de tal manera que su legitimación quedaba en suspensión en ciertos momentos de las discusiones. Se desplegaba un espacio semántico en el que los consumidores sometían -contradictoriamente- las prácticas de sobreconsumo a una valoración negativa: pasaban a identificarse por su carácter "excesivo". Los grupos introducian temáticas y usaban atractores concretos que venían a poner de manifiesto el carácter problemático e inconveniente del consumismo. Las asociaciones semánticas se producían alrededor de los tiempos del consumo, que implicaban continuadas elecciones y cambios de objeto, así como con los "ritmos acelerados de las grandes ciudades" (GD1). Los espacios y tiempos del consumo se experimentaban en forma de presión, estrés y agotamiento, contrastando con una cierta idealización de un pasado más sosegado en lo que al consumo se refiere. Para estos consumidores la acumulación irracional de objetos a la que está ligado el consumismo, así como la sobresignificación de todos los ámbitos de la vida cotidiana, resultaban, asimismo, asuntos problemáticos y negativamente connotados. Lo mismo ocurría con las valoraciones sobre el carácter pernicioso de los tópicos de la individualización y la uniformización producidos por la sociedad de consumo.

$\mathrm{H}$ : Yo veo que el consumismo se dirige al individualismo de la persona, tendemos a estar más individuales y a cerrarnos... a estar en un grupo cerrado, ese grupo cerrado es tu casa, tus hijos, tu familia y entonces todo va dirigido a este sistema, el consumismo va dirigido a eso, a tener un ordenador para distraerte tú con tus hijos, la consola de video juegos, un DVD para verlo en casa y no tener que ir al cine, canal Satélite, la ropa para sentirte tú gusto, es todo más individual, antes era más para estar todos juntos... (GD3).

H: Es que ese no es el plan. Hay muchas veces que digo: “¿para qué te compras tanto?" (GD5). 
$\mathrm{H}$ : “Yo, para mí, todo tiene un significado excesivo, a veces me veo abrumado por todo, ya tomas una decisión, compres eso, compras aquello y cobra un significado..." (GD1).

Dentro de este espacio semántico tendente a dibujar los perjuicios del consumo excesivo, aparecían en los grupos distintos relatos sobre la cuestión. Entre las clases medias (GD5, GD3) y algún núcleo de las medias-altas (GD1), emergía la idea de un malestar vinculado a la abundancia y a la experiencia de saturación simbólica y material generada por el sobreconsumo. Los consumidores expresaban una sensación de insatisfacción, vinculada a la insaciable lógica del deseo, así como un sentimiento de apatía e indiferencia asociada a no saber qué desear en el consumo. Autores como Bauman (2007) habían diagnosticado estos procesos como efectos propios de la sociedad consumista. Ello ocurría particularmente en grupos que mantenían una importante conducta de gasto y de acceso al consumo. Por ejemplo, los hijos jóvenes de las mujeres del GD5, probablemente entre los sectores sociales que más habían normalizado la cultura de consumo. Cabe recordar que la insatisfacción del consumidor había supuesto una característica estructural de la sociedad de consumo. En una etapa de acceso intensivo al consumo, podía expresarse con mayor claridad.

M: Es que no lo saben.

M: Es que él no sabe lo que quiere...

M: Tienen de todo.

$M:$...porque es que como tienen de todo.

M: De todo.

M: No es como antes, que tenías ilusión por algo... (GD5).

$\mathrm{H}$ : $\mathrm{Y}$ luego cuando lo tienes no le tienes el aprecio que cuando le necesitas (...) Iba detrás de la Seiscientos como un loco y ahora que la tengo, nada.

H: Sí, ahora ya la prioridad se pone en otro sitio, una vez tienes algo ya...

$\mathrm{H}$ : Yo creo que hemos llegado a un punto de saturación, hay tanta oferta. (GD3)

Otro de los hilos discursivos de rechazo al consumismo es el mostrado por un discurso moral que, actuando como contrapeso, revelaba normas morales opuestas a la celebración consumista. En este desarrollo, no obstante, se expresaba un fraccionamiento discursivo. Por una parte, fracciones de clases medias y mediasaltas, de forma más evidente, juzgaban moralmente el consumismo como algo "inauténtico", "asqueroso", "horroroso", "falso", afirmando incluso que se trataba de una "obsesión". En contraposición, manifestaban la necesidad de que nuevos valores alejados del consumismo brotaran con el fin de romper con cualquier imagen estandarizada de un consumo fordista degradado y masificado. Así la "sencillez", la "autenticidad", los pequeños placeres y la contención en el consumo emergían como contravalores del consumismo (GD1). En efecto, se trata de un discurso en línea con el modelo de nuevo consumidor caracterizado por dar un sentido más equilibrado a las relaciones de consumo (Rochefort, 1997; Alonso, 2005). Una línea discursiva que, en continuidad con otros trabajos, mostraba su presencia ya antes de la crisis entre los consumidores (Hampson y McGoldrich, 2013; Alaminos, 2013).

Por otra parte, entre las clases medias y medias-bajas (GD2, GD3, GD5), el discurso moral mostraba unos efectos más personalizados a nivel latente y emocional. Se construía como una suerte de 'dique de contención' (insuficiente) ante las prácticas consumistas. Al lado de la expresión de expectativas de un consumo desacomplejado como las vistas anteriormente, aparecían en estos años de bonanza momentos en que una conciencia moral (superyoica) poco racionalizada, no era capaz de traducirse en discurso articulado sobre los límites del consumo, pero en 
cambio sí de aparecer como freno más bien retórico ante las prácticas de consumo. Así se expresaba la idea latente del 'disfruta consumiendo, pero sin pasarte'. Estas fracciones de las clases medias hablaban desde el marco de experiencia que les proporcionaba su posición y trayectoria social, el cual no se correspondía con el de las clases más pudientes que décadas atrás habían alcanzado una alta capacidad de consumo (Alonso, 2005). Con los datos empíricos disponibles solo podemos inferir, provisionalmente, que estos consumidores actuaban desde un marco cultural y de clase que, más allá de las limitaciones económicas, funcionaba como contención ante lo juzgado como "consumo excesivo". Una actitud que, a su vez y contradictoriamente, a nivel latente parecía testimoniar la voracidad consumista anteriormente relatada.
H: Yo por ejemplo trabajo en la calle Colón y para mí es un tormento ir..., al salir a desayunar porque claro, tengo que estar conteniéndome todo el tiempo en no consumir (GD5).
H: "aquí hay que atarte, hay que atarte"; porque llegué y dije: "no, me voy a controlar"; porque claro, lo tienes todo al lado... (GD2).

\section{Resolución de la ambivalencia: el cínico 'consumo obligatorio'}

Los discursos analizados hasta aquí nos ponen en la pista de una ambivalencia social fundamental que atravesaba, con más o menos matices, el conjunto de los grupos de discusión. La ambivalencia se expresaba en la confrontación entre los discursos analizados: la posición de la oportunidad consumista; y la posición detractora, negativa y moralista entorno al consumismo, más marginal en el conjunto del corpus. Merton (1980) se refería a este tipo de contextos ambivalentes por la existencia de valores y normas excluyentes que exigen seguir posiciones contradictorias a los miembros de los grupos sociales. Asimismo, esta contradicción podría caracterizarse también, siguiendo a Tuckett (2011), como una relación de objeto ambivalente; es decir, por una experiencia preconsciente con el consumo que las clases medias tendrían en base a sentimientos opuestos. Lo fundamental de esta ambivalencia estaba en que la racionalización con la que se resolvía, pasaba por una actitud cínica que, en cuanto tal, situaba el cinismo no tanto en el "saber" como en el "hacer", en una ilusión que orientaba la realidad práctica (Zizek, 2017, p. 77). ${ }^{1}$ Los consumidores sabían muy bien que tenían una relación ilusoria con la realidad del consumo, una relación basada en una intensificación del consumo privado, insostenible a medio plazo, mantenido por el crédito, pero aun así en su práctica, continuaban manteniéndola.

Los consumidores expresaban la 'imposibilidad' de no quedar absolutamente absorbidos por la "ola" o la fuerte tendencia consumista predominante en esos años. El consumo se convertía de este modo en un "consumo obligatorio" al que decían que no podían -y probablemente tampoco querian- renunciar. Los consumidores resolvían así la incoherencia lingüística expresada en distintas fases del discurso. El consumo se representava como un fantasma omnipresente que todo lo dominaba, todo lo condicionaba y de cuya 'matriz' era imposible escapar. En ocasiones los sectores medios y medios-altos del GD1 y GD4 se autodenominaban "víctimas" y "engañados" por la vorágine consumista que protagonizaban; en la misma línea se pronunciaba el grupo de mujeres de clase media del GD2, denominándose "esclavas" del consumo. Estos discursos no expresaban solamente sus propias dificultades como consumidores para tener un control más racionalizado del

\footnotetext{
1 La discusión sobre la noción filosófica de cinismo es larga e inabordable en este trabajo. Algunos desarrollos recientes han venido de autores más o menos cercanos a las ciencias sociales como es el caso de Michael Foucault, el filósofo Peter Sloterijk, así como Slavoj Zizek, al que usamos en el texto. En términos muy generales, como criterio de validez de la actitud cínica entenderemos la falta de coherencia entre acción, discurso y pensamiento.
} 
gasto, sino que tendían a proyectar la determinación de sus comportamientos a un ente exterior, general y abstracto como "la sociedad" (GD2). Eran el contexto de sobreconsumo, las modas, las tendencias, las marcas, quienes los "bombardean" (GD4) y los "guían" (GD3) en el desarrollo de sus prácticas de consumo. Unas prácticas que recubrían la totalidad de campos sociales y respecto a las cuales estos consumidores pretendían -tratando de eludir la culpa-desresponsabilizarse.

M: Es que la imposición de la moda a veces te hace sentir un esclavo; un esclavo y una esclava, o sea que...

M: Yo pienso que sí.

M: Pero es que... No, pero estás condicionado totalmente (...).

M: Sí, sí. Pero también hay un momento que dices: "yo paso"; pero no. O sea, te influye.

M:...y cuando tenemos tiempo libre el tiempo de vivir lo gastamos en los centros comerciales, porque es alucinante: abren un domingo y es como la veda se ha abierto.

M: Qué horror. Qué horror. Qué horror. Sí. Eso sí.

M: Es de susto.

M: Es de susto. A gastar y a consumir. A gastar todo lo que has ganado...

M: ¿Necesitamos tantas cosas?

M: Pero es la sociedad. Es la sociedad. Nos lleva la sociedad a decir: Bueno, ¿qué hacemos hoy? ¿Están abiertos los centros comerciales? A comprar

M: Uno ser ve tan mono... (GD2).

M: ...por eso yo creo que algunos somos adictos o buscamos la marca, porque te da esa garantía; que nos engañan totalmente.

M- Vilmente.

M: Sí; pero somos víctimas de esa asociación

H: ...las tendencias están ahí, y tú no puedes...

En fin... Pero todo se carga de significado, y en ese sentido las tendencias al final, efectivamente, a lo mejor no por seguirlas, pero sí por negarlas, acabas estando metido en una tendencia, en la versión negativa de la tendencia, en el: no soy de ellos o no estoy ahí; pero estás ahí, ¿no? "Yo no voy a Ikea"; y entonces haces de eso, o acabas haciendo una especie de bandera (GD1).

A través de este discurso determinista, que puede recordar las versiones más "apocalípticas" criticadas por Umberto Eco, usadas aquí de modo cínico, los consumidores racionalizaban su posición consumista aduciendo la imposibilidad de prescindir de la sucesiva cantidad de productos que aparecían en el mercado ("te obligan a reponer", "tendrás que comprar en algún momento", GD4). Una dificultad que se justificaba por la falta de control que como consumidores tenían sobre la producción de necesidades por parte de la oferta. A pesar de que ello podría interpretarse como una demanda latente de mayor democratización en el desarrollo de los modelos de producción-consumo, las evidencias empíricas aportadas por los grupos muestran sin embrago la incapacidad de los consumidores de elaborar una mínima noción colectiva de necesidades, ni plantear límites claros al consumismo. A pesar de cuestionar cínicamente la producción del sistema de necesidades de la sociedad de consumo, inmediatamente rechazaban cualquier tipo de limitación en este sentido, por lo que la lógica del deseo adquiría prioridad. Con ello expresaban, a pesar de las críticas, la incuestionable participación en la 
actividad consumista so pena de aceptar la pérdida de valor social, así como de satisfacciones vinculadas al consumo.

M: Igual me lo pongo dos veces, pero es que me he enamorado de eso.

M: Es que lo necesito, ¿no?

$M:$ Es que, si te enamoras, te enamoras.

M: La duda es si crean una necesidad que no tenemos o descubren necesidades que tenemos y nos facilitan la vida.

$\mathrm{H}$ : Yo creo que crean necesidades que realmente no tenemos; pero al final, una vez que te acostumbras, ya no puedes vivir sin ellas.... (GD2).

Un desarrollo del mismo ideologema del control por parte de la oferta lo realizan las clases medias-altas (GD4) trayendo a colación la idea de la obsolescencia programada. Esta no se usaba tanto para señalar las consecuencias desiguales que entraña la esfera del consumo cuando tiende a multiplicar las jerarquías sociales; sino más bien con el fin de externalizar las responsabilidades y justificar su propia e "inevitable" implicación con el sobreconsumo. Siguiendo prácticamente al pie de la letra las dimensiones que la sociología del consumo había descrito a propósito de la obsolescencia de los productos (Packard, 1961), los discursos desarrollan reflexivamente tres hilos discursivos al respecto:

1) las "estrategias prediseñadas" omnipotentemente por la oferta, consiguiendo el control sobre el consumo de tecnologías;

2) la escasa durabilidad de los productos y el sinsentido económico (desde una perspectiva maximizadora), que a veces suponía intentar su reparación, cuando reparar resultaba más costoso que adquirir un producto nuevo;

3) los cambios de diseño material y simbólico de los productos y la omnipresencia de la publicidad en sus vidas que "obligan" a consumir y cambiar de productos constantemente.

El consumo y los distintos planos con los que se configura su cultura ejercían una potente e ineludible influencia -como señalan concretamente los grupos-: en la compra y decoración de un piso, en el consumo y valoración de los coches, en la alimentación, el ocio, el cuidado y transformación corporal, en las identidades de los consumidores, etc. Este relato señalaba, además, la "obligación" a la que estaban sometidos los consumidores en determinados segmentos punteros como el de los objetos tecnológicos y de comunicación. Se percibía la obligación de tener que mantenerse actualizado en materia tecnológica (móviles, internet, etc.) con el fin de poder usar las potencialidades de los productos. De lo contrario, se corría el riesgo de quedar "desconectado", incluso relacionalmente hablando, por el efecto dependencia creado por el renovado abanico de nuevos objetos fáticos de consumo (Conde y Alonso, 2002). Las exigencias derivadas del trabajo y su relación con los códigos de vestimenta e imagen que relatan las mujeres del GD5 se apoyaban -y legitimaban-también en la idea de la obligación.

Según nuestro análisis, los consumidores del conjunto de las clases medias analizadas no estaban dispuestos a renunciar, aunque se mostrasen conscientes de la posibilidad y pertinencia de hacerlo, a los propios deseos de consumir, ni a abandonar el despliegue de sus capitales y capacidades en la carrera simbólica del consumo. La lógica del deseo se expresaba como inevitable, irremediable, y sobre la misma se desarrollaba el tipo de consumo predominante en estos años anteriores a la crisis: "si te enamoras [de un objeto] te enamoras..." (GD2); "se nos antoja... y quieres ampliar un poco todo" (GD4); "Yo pienso que la mayoría nos damos los caprichos que queremos, en ge..., dentro de una línea, claro" (GD5). 
En las posiciones medias-altas (GD4 y GD1) se articulaba además la crítica al sobreconsumo con la idea que el modelo consumista había conllevado el acceso masivo, antes reservado a sectores sociales más elevados, a determinados consumos ociosos y superfluos, con la consiguiente indiferenciación que ello acarreaba. Ello hacía que estos consumidores, siguiendo la línea interpretativa de Bourdieu (1988) y de trabajos recientes (Curridt-Halkett, 2017), se vieran impelidos a emprender nuevas estrategias de reposicionamiento social y simbólico a través del consumo ante la creciente competitividad consumista que suponía el acceso de capas medias y medias bajas a consumos que tradicionalmente cumplían con una función distintiva. Una interpretación que ha resultado ser consistente con la mostrada por Conde (2020) sobre la estrategia de distinción de estos grupos sociales.

M: ...lo siento, que puedo parecer un poco snob, pero la moda del vino ahora; que siempre ha existido (...). La gente lo ve como algo nuevo cuando siempre ha existido, lo que pasa que volvemos a lo mismo, hoy en día todo se ha masificado, todo se ha extendido a mucha gente (GD1).

$\mathrm{H}$ : Ya, pero eso es diferente es ahora el decir: "he ido a esquiar", "he ido a jugar a golf", que ahora el golf de repente ha salido aquí por todos los sitios, parece que todo el mundo está practicando el swing, a ver cómo... Pues mira, chico, pues son temporadas y sobre todo que ya es la demanda: la casa con el golf, el no sé qué... (GD4).

\section{CONCLUSIONES: DEL CINISMO A LA CRISIS ECONÓMICA}

El carácter cínico con el que se había resuelto la ambivalencia en los discursos sirvió como eje sobre el que los consumidores se imaginaban el futuro en general, y el futuro del consumo en particular. En prácticamente todos los grupos se señalaba que la evolución de la sociedad estaría fatalmente marcada por el desarrollo excesivo que había tomado el consumo en estos últimos años ("No podemos llevar ese ritmo durante tantos años", GD2; "en mis días veré el final de esto", GD1). A pesar de ello, este tipo de valoraciones no habían servido para contrarrestar los discursos más proclives a la lógica consumista, ni mucho menos a contener los comportamientos consumistas. Estos consumidores se mostraban incrédulos y desconfiados con que el contexto consumista pudiera prolongarse en el tiempo. Lo que estaba por venir -observaban- se acercaba más a una crisis, a la imagen de un corte social y económico. Prácticamente todos los grupos coincidían en pronosticar un fin al consumismo del que activamente estaban participando. No se trataba, no obstante, de un final deseado, sino de la creencia en la insostenible evolución de la misma sociedad. El grupo de mujeres de clase media-media auguraban un futuro con unos ritmos de consumo más lentos que obligarían de algún modo a "apearse" (GD2). De ahí que los grupos señalasen la idea de que estaban viviendo en una cierta "ficción", como recogen trabajos posteriores (Callejo, 2010; Alonso et al., 2015).

En la misma línea, el pronóstico de futuro en el GD3 de clases medias y mediasbajas apuntaba ya, con un sorprendente nivel de acierto, a la crisis económica, la bajada del consumo y la paulatina desaparición de las clases medias. Así desarrollaban un relato sobre el carácter cíclico de las crisis económicas que se acercaba a algunas de las teorías económicas sobre la recesión (p.e. los efectos Minsky) al dibujar una sucesión de etapas de crecimiento y crisis, seguidas del aumento de la desigualdad y la polarización social. El discurso de estos participantes, poco acostumbrados la mayoría de ellos al promocionismo y al derroche, conseguía articular una idea de límite temporal al consumismo. Una imagen que describía la implosión de la lógica consumista pero no así de 
la sociedad de consumo. Para ésta se preveía, aunque con nuevas condiciones sociales, una revitalización cíclica sin fin. Así desde el GD3 se anticipaba de modo realista -podemos decir con la perspectiva del tiempo- los hallazgos y contribuciones que la literatura viene realizando en los últimos años sobre el declive de las clases medias y el papel que en dicho proceso juega el consumo, tanto en España como en otros países occidentales (Alonso et al., 2017; Vihalemm et al., 2016).

H: Sí, muy diversificados, mucha riqueza y mucha pobreza. Lo que se tiende es que al término medio vaya desapareciendo cada vez más (...).

H: Creo que será una rueda, volverá a ser una rueda, antes cuando salieron los coches la gente no se podía comprar coches y estaban bien diferenciados, no había clase media, había baja y alta, la clase baja empezó a crecer poco a poco y nació la clase media y empezaron a comprarse coches y nació el consumismo a tope, (...) entonces como igual que la moda da vueltas el consumismo dará una vuelta, sufrirá un parón y luego volveremos a arrancar otra vez, el problema es saber dónde estaremos si en la clase tirando a contrabajo o la clase contrabajo, bajo... entonces los de clase que trabajen y tengan dinero no podrán absorber todo el consumismo, todo lo de las empresas, creo que acabaremos parando ahí, luego dónde llegaremos, volver a empezar, consumir poco a poco, bajar precios y dar una vuelta (GD3).

Los resultados aportados hasta aquí evidencian la cercanía entre los discursos analizados y la citada fórmula empleada por el filósofo esloveno Slavoj Zizek (2017) para referirse al funcionamiento cínico de la ideología: "ellos saben lo que hacen (siguen una ilusión), pero aun así, lo hacen". Una máxima que sintetiza el papel que jugaban por lo menos una parte de las clases medias españolas ante el consumo en los años del cambio de siglo. Asumían el carácter consumista excesivo de sus prácticas, juzgadas a veces como moralmente rechazables, consecuencia de una situación ilusoria y difícil de prolongar indefinidamente, que terminaba con las perspectivas de futuro; pero aun así consumían ostensiblemente, a crédito, entendiendo este momento consumista como una deseada oportunidad.

Desde esta perspectiva, las clases medias se encontraban estructuralmente inscritas en una posición que pedía, para la reproducción social del modelo neocapitalista de consumo (Harvey, 2016), la inversión deseante, de intereses, argumentos (y dinero) en el consumo, cuando lo que pretendían era conseguir mayores cuotas de valorización y reconocimiento social, así como realizar un sinfín de deseos. Si el consumo se había erigido como el principal campo de batalla simbólico entre grupos sociales y estilos de vida era razonable, no obstante -desde una racionalidad socialmente contextualizada-, la necesidad de desenvolverse en este hegemónico campo del consumo. Pero como hemos visto, las restricciones y la falta de posibilidades de consumo que se establece con la llegada de la crisis, suponen un cambio de las reglas del juego, expresado en distintos cortes ideológicos como los que resumimos a continuación (véase tabla 2).

Algunos de estos cortes pueden proyectarse como líneas futuras de investigación con el fin de calibrar la evolución discursiva sobre el consumo en las clases medias con la nueva crisis del COVID19. Si el paso de un discurso cínico a uno basado en el disciplinamiento sugiere que parte de las clases medias españolas habrían vivido, con la recesión de 2008, un proceso marcado por la hyseteris (Graham, 2020), por el cual se relataban experiencias negativas ante el consumo (una valoración moralizante con respecto el "exceso anterior", disminución del consumo y falta de control sobre el gasto, ausencia de esperanza a corto plazo...), queda pendiente analizar si la salida de la crisis de la pandemia en estos sectores sociales seguirá este modelo o, más bien, como ha ocurrido en otros sectores (Arnal et al., 2020), se desarrollaran procesos resilientes que planteen adaptaciones y experiencias positivas y alternativas ante el consumo. 
Tabla 2. Cortes y continuidades en los discursos de las clases medias sobre el consumo antes y después de la crisis de 2008

CORTES ARGUMENTATIVOS E IDEOLÓGICOS EN LOS DISCURSOS DE LAS CLASES MEDIAS SOBRE EL CONSUMISMO

\begin{tabular}{|c|c|}
\hline ANTES CRISIS ECONÓMICA 2008 & $\begin{array}{l}\text { DESPUÉS INICIO CRISIS ECONÓMICA 2008 } \\
\text { (Alonso et. al 2011; 2016a y b; 2017; Callejo, 2010) }\end{array}$ \\
\hline $\begin{array}{l}\text { 1. Discurso cínico ante el consumo como salida a la } \\
\text { ambivalencia: } \\
\text { a. Oportunismo ante el consumo ocioso ("Y por que } \\
\text { no?") vs rechazo y crítica al consumismo. } \\
\text { b. 'Consumo obligatorió: imposibilidad de no } \\
\text { consumir. }\end{array}$ & $\begin{array}{l}\text { 1. Disciplinamiento en el consumo como efecto } \\
\text { de la crisis: } \\
\text { a. Moral colectivamente culpabilizadora } \\
\text { respecto al exceso en el consumo. } \\
\text { b. Resignación reajustable hábitos consumo. }\end{array}$ \\
\hline $\begin{array}{l}\text { 2. Carácter abierto y flexible norma de consumo: } \\
\text { contexto favorable y posibilidades diversas y } \\
\text { legítimas. } \\
\text { a. Oferta amplia de consumo como libertad de } \\
\text { elección y configuración identidad. } \\
\text { b. Legitimación del gasto superfluo. } \\
\text { c. Concepción ahorro como gasto diferido. }\end{array}$ & $\begin{array}{l}\text { 2. Carácter cerrado y cristalizado de la norma } \\
\text { de consumo: exceso es transgresión ilegítima. } \\
\text { a. Legitimación de la austeridad y la } \\
\text { contención del gasto. } \\
\text { b. Concepción ahorro como necesidad. }\end{array}$ \\
\hline $\begin{array}{l}\text { 3. Legitimación de deseos consumistas y de } \\
\text { estrategias simbólicas en el consumo. } \\
\text { a. Diferenciación particularista mediante el } \\
\text { consumo. } \\
\text { b. Renclasamiento (ascendente) mediante el } \\
\text { consumo de las clases medias-altas. }\end{array}$ & $\begin{array}{l}\text { 3. Ilegitimidad de dar rienda suelta al deseo } \\
\text { consumista y a estrategias de diferenciación } \\
\text { inasumibles. } \\
\text { a. Autocontrol y castigo ante el consumismo } \\
\text { del pasado. } \\
\text { b. Desclasamiento real de las clases medias. }\end{array}$ \\
\hline \multicolumn{2}{|c|}{ CONTINUIDADES DISCURSOS PRE Y POSCRISIS 2008} \\
\hline \multicolumn{2}{|c|}{$\begin{array}{l}\text { 1. Referencia simbólica central del consumo } \\
\text { a. Sociedad de consumo único, aunque confases de crisis y desarrollo. } \\
\text { b. Carácter de ficción y fantasía del sobreconsumo: dificil prolongación. } \\
\text { c. Incapacidad de definir colectivamente límites al consumo, y a las necesidades. }\end{array}$} \\
\hline \multicolumn{2}{|c|}{ 2. Singularidad modelo de consumo en España: precios y mentalidad } \\
\hline $\begin{array}{r}\text { 3. De una moral emocionalmente personalizada c } \\
\text { desarrollada y proyectada colectivam }\end{array}$ & $\begin{array}{l}\text { mo "dique" al deseo consumista a una moral } \\
\text { nte contra el exceso consumista. }\end{array}$ \\
\hline
\end{tabular}

Fuente: Elaboración propia.

\section{AGRADECIMIENTOS}

Agradezco la amabilidad de Fernando Conde quien ha proporcionado desinteresadamente los datos que constituyen la base empírica de este trabajo.

\section{REFERENCIAS}

Alaminos, A. (2013). La futura vida cotidiana en España: la sociedad de consumo. Obets, Revista de Ciencias Sociales, 8(1): 15-58. https://doi.org/10.14198/OBETS2013.8.1.01

Alonso, L. E. (2013). La sociohermenéutica como programa de investigación en sociología. ARBOR, 189(761): a035. https://doi.org/10.3989/arbor.2013.761n3003 
Alonso, L. E. (2005). La era del consumo. Madrid: Siglo XXI.

Alonso, L. E. (2016). "El consumo obligatorio o la lógica de la sociedad de pago". En E. Gil Calvo (Coord.) Sociólogos contra el economicismo (pp. 129-155). Madrid: Catarata.

Alonso, L. E., y Fernández Rodríguez, C. J. (2020). La vía semiperiférica hacia la sociedad de consumo: una interpretación sobre el modelo español. Revista Española De Sociología, 29(3 - Sup1), 197-214. https://doi.org/10.22325/fes/res.2020.65

Alonso, L. E., y Fernández Rodríguez, C.J. (2018). Poder y Sacrificio. Los discursos de la empresa. Madrid: Siglo XXI.

Alonso, L. E., Fernández Rodríguez, C. J. \& Ibáñez Rojo, R. (2015). From consumerism to guilt: Economic crisis and discourses about consumption in Spain. Journal of Consumer Culture, 15(1), 66-85. https://doi.org/10.1177\%2F1469540513493203

Alonso, L. E., Fernández Rodríguez, C. J. y Ibáñez Rojo, R. (2016b). Entre la austeridad y el malestar: discursos sobre consumo y crisis económica en España. Revista Española de Investigaciones Sociológicas (REIS), (155), 21-36. https://dialnet.unirioja.es/descarga/ articulo/5834068.pdf

Alonso, L. E., Fernández Rodríguez, C. J., y Ibáñez Rojo, R. (2016a). De la moral del sacrificio a la conciencia de la precariedad. Un análisis cualitativo de los discursos sobre la evolución de la crisis en España. Política y Sociedad, 53(2), 353-379. https://doi. org/10.5209/rev_POSO.2016.v53.n2.49380

Alonso, L., Rodríguez, C.J., \& Rojo, R.I. (2017). "I think the middle class is disappearing": Crisis perceptions and consumption patterns in Spain. International Journal of Consumer Studies, 41, 389-396. https://doi.org/10.1111/IJCS.12352

Angelini, V., Brugiavini, A., \& Weber, G. (2013). Household consumption and the crisis. En A. Börsch-Supan, M. Brandt, H. Litwin, \& G. Weber (Edits.), Active ageing and solidarity between generations in Europe: First results from SHARE after the economic crisis (pp. 19-26). Berlin: Walter de Gruyter.

Angenot, M. (2010). El discurso social. Madrid: Siglo XXI.

Arnal, M., De Castro, C., \& Martín, M. P. (2020). Consumption as a social integration strategy in times of crisis: The case of vulnerable households. International Journal of Consumer Studies, 44(1), 1-11. https://doi.org/10.1111/ijcs.12550

Atkinson, W. (2013). Economic crisis and classed everyday life: hysteresis, positional suffering and symbolic violence. En W. Atkinson, S. Roberts, \& M. Savage, Class Inequality in Austerity Britain (pp. 13-32). London: Palgrave.

Bauman. Z. (2007). La vida de consumo. Madrid: Fondo de Cultura Económica.

Bourdieu, P. (1988). La distinción. Madrid: Taurus.

Brändle, G. (2010). El consumo en tiempos de crisis: una aproximación sociológica a la distribución del gasto en España. Aposta: Revista de Ciencias Sociales, (45), 1-24. https://dialnet.unirioja.es/servlet/articulo?codigo $=3184483 \&$ orden $=247838 \&$ info=link

Broost, M., \& Meier, L. (2016). Resilient practices of consumption in times of crisisBiographical interviews with members of vulnerable households in Germany. International Journal of Consumer Studies, 41(4), 371-378. https://doi.org/10.1111/ ijcs.12346 
Callejo, J. (junio de 2010). Las contradicciones de la sociedad de consumo en escenarios de crisis (o la lógica contradictoria de la sociedad de consumo). X Congreso Español de Sociología. Pamplona.

Conde, F. y Alonso, L. E. (2002). Gente conectada: la emergencia de la dimensión fática en el modelo de consumo glocal. Política y Sociedad, 39(1): 27-51. https://revistas.ucm.es/ index.php/POSO/article/view/POSO0202130027A

Conde, F. (2009). Análisis Sociológico del Sistema de Discursos. Madrid: CIS.

Conde, F. (2020). Una reflexión sobre los procesos de cambio en las pautas de consumo. Los regímenes de historicidad en el consumo. En L. E. Alonso, C. J. Fernández Rodríguez, y R. Ibáñez Rojo (Edits.), Estudios sociales sobre el consumo (pp. 29-52). Madrid: CIS.

Curridt-Halkett, E. (2017). The Sum of Small Things A Theory of the Aspirational Class. Princeton: Princeton University Press.

Davidson, E., Edwards, R., Jamieson, L., \& Weller, S. (2020). Big data, qualitative style: a breadth-and-depth method for working with large amounts of secondary qualitative data. Quality and Quantity, (53), 363-376. https://doi.org/10.1007/s11135-018-0757-y

Gaggi, M., y Narduzzi, E. (2006). El fin de la clase media. Madrid: Lengua de Trapo.

Graham, H. (2020). Hysteresis and the sociological perspective in a time of crisis. Acta sociologica, 63(4), 450-452. https://doi.org/10.1177\%2F0001699320961814

Häkanson, A. (2014). What is overconsumption? A step towards a common understanding. International Journal of Consumer Studies, 38(6), 692-700. https://doi.org/10.1111/ ijcs.12142

Hampson, D. P., \& McGoldrick, P. J. (2013). A typology of adaptive shopping patterns in recession. Journal of Business Research, 66(7), 831-838. https://doi.org/10.1016/j. jbusres.2011.06.008

Harvey, D. (2016). El enigma del capital. Madrid: Akal.

Hughes, K., \& Tarrant, A. (2019). Qualitative Secondary Analysis. London: Sage.

Ibáñez, J. (1979). Más allá del grupo de la sociología. El grupo de discusión: técnica y crítica. Madrid: Siglo XXI.

Koos, S. (2017). Crises and consumption. En M. Keller, B. Halkier, T. A. Wilska, \& M. Truninger (Edits.), Routledge Handbook on Consumption (pp. 106-115). London: Routledge.

Lawler, S. (2005). Disgusted subjects: the making of middle-class identities. Sociological Review, 53(3), 429-446. https://doi.org/10.1111\%2Fj.1467-954X.2005.00560.x

Lekakis, E. J. (2015). Economic nationalism and the cultural politics of consumption under austerity: The rise of ethnocentric consumption in Greece. Journal of Consumer Culture, 17(2), 286-302. https://doi.org/10.1177\%2F1469540515586872

Lopes, C. A., \& Frade, C. (2012). The way into bankruptcy: market anomie and sacrifice among Portuguese consumers. Journal of Consumer Policy, 35(4): 477-496. https://doi. org/10.1007/s10603-012-9212-y

López, I., y Rodríguez, E. (2010). Fin de ciclo. Financiarización, territorio y sociedad de propietarios en la onda larga del capitalismo hispano (1959-2010). Madrid: Traficantes de Sueños.

Merton, R. K. (1980). Ambivalencia sociológica y otros ensayos. Madrid: Espasa-Calpe. 
Ortí, A. (1992). Para una teoría de la sociedad de clases medias de los 80. Documentación Social, (88), 209-234.

Ortí, A. (2014). Encuestación cualitativa y praxis socioinstitucional: de la configuración de subjetividades sociales a la de discursos virtuales. Arxius de Ciències Socials, (31), 2756. http://hdl.handle.net/10550/44309

Packard, V. (1961). Las formas ocultas de la propaganda. Buenos Aires. Editorial Sudamericana.

Ricoeur, P. (2001). Del texto a la acción. Madrid: FCE.

Ricoeur, P. (2004). Tiempo y narración I. México: Siglo XXI.

Rochefort, R. (1997). Le consommateur entrepeneur. París: Odioe Jacob.

Salido, O. (2012). Los ciudadanos españoles antes la crisis. Madrid: Fundación Alternativas.

Skeggs, B. (2004). Class, Self, Culture. London: Routledge.

Tuckett, D. (2011). Minding the Markets. An Emotional Finance View of Financial Instability. London: Pallgrave.

Vihalemm, T., Keller, M., \& Pihu, K. (2016). Consumers during the 2008-2011 Economic Crisis in Estonia: Mainstream and Grass Roots Media Discourses. Italian Sociological Review, 6(1), 57-86. https://doi.org/10.13136/isr.v6i1.123

Zizek, S. (2017). Porque no saben lo que hacen. El sinthome ideológico. Madrid: Akal.

\section{NOTA BIOGRÁFICA}

Marc Barbeta Viñas es Profesor asociado en la Universitat Autònoma de Barcelona y la Universitat de Girona. Es investigador en el departamento de sociología de la UAB. Las principales líneas de investigación son: la sociología del consumo y la cultura, así como los métodos y técnicas de investigación cualitativa. También ha trabajado en investigaciones en el ámbito de la familia, el género, la educación y la desigualdad social. 